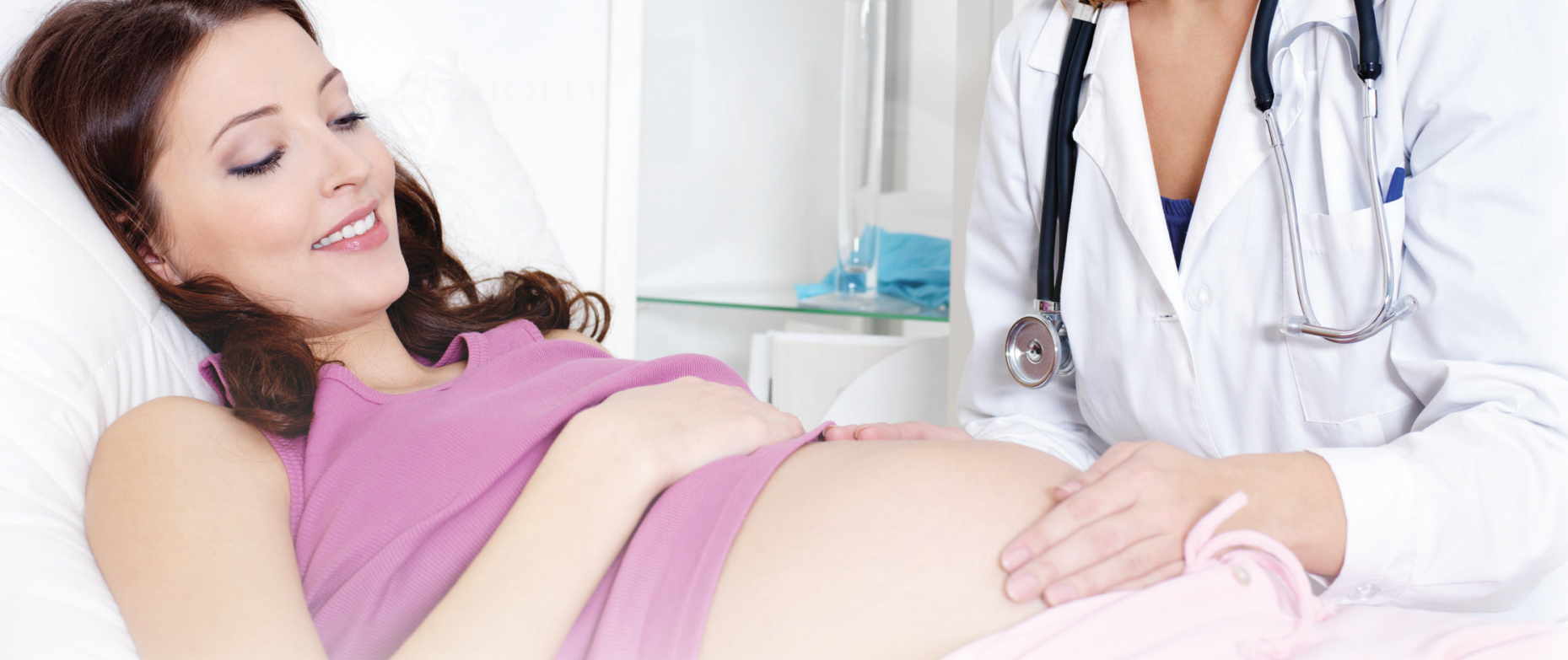

НУЖНО ЛИ ЛЕЧИТЬ ЛЕГКУЮ ПРЕЭКЛАМПСИЮ?

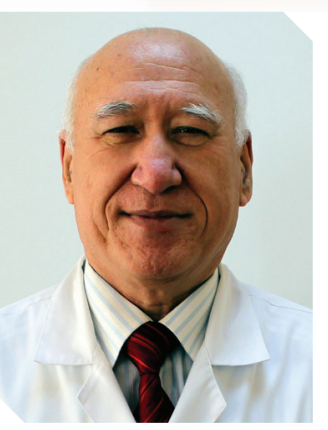

\section{A.X. КАРИМОВ}

д. мед. н., профессор кафедры акушерства и гинекологии №2 Ташкентской медицинской академии, Узбекистан

\section{Г.А. АХМЕДОВА}

ассистент кафедры акушерства и гинекологии №2 Ташкентской медицинской академии, Узбекистан

Контакты:

Каримов Ахмад Хошимович

2-я клиника Ташкентской

медицинской академии

Алмазарский район, ул. Фароби, 2 100109, Ташкент, Узбекистан тел.: +998 (71) 1509550

e-mail: Akhmadjon.Karimov@tma.uz

\section{ВВЕДЕНИЕ И ПОСТАНОВКА ЗАДАЧИ ИССЛЕДОВАНИЯ}

Преэклампсия и эклампсия являются самыми распространенными причинами гестационных осложнений как для матери, так и для плода [1, 4]. Основной причиной этих состояний считают прикрепление плаценты, которое характеризуется нарушенной инвазией трофобластных клеток и изменением маточной сосудистой системы, что приводит к снижению маточноплацентарного кровотока и в результате - к сужению кровеносных сосудов матери и разрушению эндотелиальных клеток [3]. Эндотелий является основным объектом медиаторов, которые вырабатываются плацентой. Также есть и другие факторы, такие как активные формы кислорода, усугубляющие нарушения. Оксид азота (NO) - это сильнодействующее эндотелиальное сосудорасширяющее средство. Определено, что неполноценный синтез оксида азота может быть причиной преэклампсии [2]. Синтез NO происходит из L-аргинина с помощью ферментов NO-синтаз в клетках эндотелия сосудов. Кроме того, преэклампсия может возникать вследствие повышенной концентрации факторов, угнетающих выработку оксида азота [3].

Согласно результатам конфиденциального аудита материнской смертности от преэклампсии в регионах России в 2016 г. [4], основными причинами материнской смертности от преэклампсии/эклампсии по-прежнему являются отсутствие прогнозирования преэклампсии; запоздалая диагностика легкой преэклампсии и недооценка ее тяжести; недостаточное и несвоевременное обследование; запоздалое родоразрешение; прекращение магнезиальной терапии во время и после родоразрешения. Предотвратимость и условная предотвратимость материнской смертности от преэклампсии/эклампсии составила 75,5\%.
Согласно клиническим протоколам, утвержденным Минздравом Республики Узбекистан, легкую преэклампсию лечить не надо - необходимо наблюдать за артериальным давлением (АД), протеинурией. При симптомах тяжелой преэклампсии лечение необходимо начинать с магнезиальной терапии.

Целью исследования стало изучение вопроса о необходимости лечения легкой преэклампсии.

\section{МАТЕРИАЛ И МЕТОДЫ ИССЛЕДОВАНИЯ}

Под наблюдением находились 68 женщин в третьем триместре беременности, поступивших в 2015-2016 гг. в отделение патологии акушерского комплекса 2-й клиники Ташкентской медицинской академии с диагнозом легкая преэклампсия. Критериями для госпитализации были гипертензия (систолическое АД $\geq$ 140 мм рт. ст., диастолическое АД $\geq 90$ мм рт. ст. или и то, и другое) либо протеинурия ( $\geq 300$ мг/24 часа), диагностированные после 20 недель беременности у женщин с нормальным АД до беременности. Легкая преэклампсия включала такие симптомы, как гипертензия и протеинурия на фоне анемии, пиелонефрита, острой респираторной инфекции. Было также изучено несколько неонатальных исходов, включая преждевременные родоразрешения (до 37 недель беременности), небольшая для гестационного периода масса тела при рождении и количество баллов по шкале Апгар.

Беременные были разделены на две группы: 1 (группа сравнения) - 30 беременных с легкой преэклампсией, ведение которых осуществлялось согласно клиническим протоколам (измерение АД, протеинурии); 2 (основная группа) 38 беременных с легкой преэклампсией, которые получали L-аргинин в сочетании с комплексом антиоксидантных витаминов. 
В нормально функционирующем эндотелии низкие уровни NO постоянно высвобождаются для поддержания кровеносных сосудов в состоянии дилатации и обеспечения неадгезивности эндотелия по отношению к форменным элементам крови. При воздействии различных повреждающих факторов (механических, инфекционных, обменных, иммунокомплексных и т. д.) способность эндотелиальных клеток освобождать релаксирующие факторы уменьшается, тогда как образование сосудосуживающих факторов сохраняется или увеличивается, т. е. формируется состояние, определяемое как эндотелиальная дисфункция [1, 3]. NO в организме человека синтезируется из аминокислоты L-аргинина под влиянием ферментов NOсинтаз (NOS). Следовательно, эта незаменимая аминокислота является субстратом для синтеза NO, и ее применение оказывает положительное воздействие на функцию сосудистого эндотелия, улучшая эндотелий-зависимую вазодилатацию.

L-аргинин зарегистрирован в Республике Узбекистан в виде 4,2\% раствора для инфузий и известен под названием Тивортин ${ }^{\circledR}$ («Юрия-Фарм», Украина), а также Тивортин аспартат, который принимают по 5 мл 4 раза в сутки per os. Препарат обеспечивает организм материалом для синтеза NO. Большое внимание уделялось и уделяется влиянию биорегуляторной системы L-аргинин-NO на маточно-плацентарный кровоток и внутриутробное развитие плода. Усиление высвобождения NO, вызванное L-аргинином, может способствовать улучшению эндотелиальной функции у беременных и действовать как антиоксидант.

В наших исследованиях лечение во 2 группе проводилось в 2 этапа (Тивортин ${ }^{\circledR}+$ комплекс антиоксидантных витаминов): 1 этап - вливание внутривенно капельно 100 мл Тивортина 1 раз в сутки в течение 7-10 дней; 2 этап Тивортин аспартат по 5 мл 4 раза в сутки per os (завтрак, обед, ужин и перед сном) в течение 20 дней.

\section{РЕЗУЛЬТАТЫ ИССЛЕДОВАНИЯ И ИХ ОБСУЖДЕНИЕ}

В клиническое исследование были включены беременные в возрасте от 18 до 40 лет. Средний возраст основной группы (2) составил 26 лет, группы сравнения (1) - 27 лет. Наибольшую часть женщин обеих групп составляли пациентки 23-33 лет. При этом перво- и повторнобеременными являлись 51,7\% и 50,0\% женщин соответственно. При изучении гинекологического анамнеза обследованных женщин установлено, что хроническим сальпингоофоритом страдают 14 (36,6\%) пациенток основной группы и 13 $(43,3 \%)$ группы сравнения; эрозию шейки матки лечили соответственно 9 (23,6\%) и 8 (26,6\%); медицинские аборты делали 23,5\% пациенток основной группы и 26,6\% группы сравнения. По показателям гинекологических заболеваний в анамнезе группы статистически значимо не различались. Наиболее часто в анамнезе беременных обеих групп отмечались заболевания сердечно-сосудистой $(42,2 \%)$ и эндокринной $(26,6 \%)$ систем. У первобеременных и первородящих частота легкой преэклампсии была выше, чем у повторнобеременных и повторнородящих.

В ходе исследования у 18 женщин 1 группы, которых на- блюдали согласно протоколам (измеряли АД, суточную протеинурию), было отмечено прогрессирование преэклампсии. Этих больных, которым был выставлен диагноз тяжелая преэклампсия, после нагрузочной дозы магнезиальной терапии перевели в реанимационное отделение и в течение 24 часов, согласно клиническим протоколам, родоразрешали путем индукции родов (введением вагинальных таблеток Гландин E2) или операции кесарева сечения (при отсутствии эффекта от простагландинов).

Пациенткам 2 группы, кроме измерения АД и суточной протеинурии, вводили Тивортин ${ }^{\circledR}$ и комплекс антиоксидантных витаминов. У всех женщин, в отношении которых проводилось вышеуказанное лечение, прогрессирования преэклампсии не наблюдалось, беременность пролонгировали до жизнеспособного срока плода. Помимо наблюдения за АД и протеинурией, эффективность лечения контролировали проведением допплерографии с цветным допплеровским картированием и допплерометрией сосудов матери, плаценты и плода.

Тивортин $^{\circledR}$ улучшил показатели допплерометрии при повторном исследовании через 2 недели: усиление кровотока в плаценте на 33\%, снижение признаков гипоксии на $20 \%$, нормализация сосудистого сопротивления в спиральных артериях матки и артериях пуповины, рост диастолического кровотока до 60,9 + 2,46 м/сек, снижение индекса резистентности до 0,35 + 0,21, снижение систоло-диастолического отношения до 1,54 + 0,34.

Повторное допплерометрическое исследование кровотока в системе мать-плацента-плод доказало высокую клиническую эффективность Тивортина в коррекции гемодинамических нарушений как в маточных артериях, так и в сосудах плода.

Применение Тивортина улучшило внутриутробное состояние плода: так, было отмечено уменьшение признаков внутриутробной гипотрофии на 15\%, снижение частоты развития синдрома ограничения роста плода (СОРП) в 3 раза, снижение частоты дистресса плода на $12 \%$.

Таким образом, беременных с легкой преэклампсией с высоким риском развития тяжелой преэклампсии и эклампсии необходимо госпитализировать в стационар для полного обследования и проведения лечения путем введения L-apгинина + комплекса антиоксидантных витаминов.

\section{ВЫводы}

1. Наличие субстрата для синтеза азота (L-аргинин) пролонгирует время до развития тяжелой преэклампсии у группы женщин высокого риска, которые принимают аминокислоту вместе с антиоксидантными витаминами. Это способствует снижению риска развития эклампсии.

2. Тивортин ${ }^{\circledR}$ как донатор NO оказывает выраженное влияние на сосудистый тонус как маточных артерий, так и артерий пуповины, способствуя нормализации гемодинамики в системе мать-плацента-плод и рождению здорового ребенка.

3. Своевременное диагностирование факторов риска развития гестоза беременности способствует повышению качества охраны здоровья матери и ребенка. 
1. Mignini, L.E., Villar, J., Khan, M.S.

"Mapping the theories of pre-eclamsia: the need for systematic reviews of mechanisms of the disease." Am J Obstet Gynecol 194 (2006): 317-21.

2. Sibai, B., Dikker, G., Kupferminc, M.

"Pre-eclampsia." Lancet 365 (2005): 785-99.

3. Moris, N., Eaton, B.M.

"Natric oxide, the endothelium, pregnancy, pre-eclampcia." Br J Obstet Gynaecol 103 (1996): $4-15$.
4. Сидорова, И.С.

Результаты аудита материнской смертности от преэклампсии в регионах России в 2016 г. И.С. Сидорова, О.С. Филиппов, Н.А. Никитина // Материалы XI международного конгресса по репродуктивной медицине, Москва, 17-20 января 2017 г. - С. 5-7.

Sidorova, I.S., Filippov, O.S., Nikitina, N.A.

"The results of the audit of maternal mortality from pre-eclampsia in the regions of Russia in 2016." Materials of the XI International Congress on Reproductive Medicine, Moscow, Jan 17-20 (2017): 5-7. i

\section{НУЖНО ЛИ ЛЕЧИТЬ ЛЕГКУЮ ПРЕЭКЛАМПСИЮ?}

А.Х. Каримов, д. мед. н., профессор кафедры акушерства и гинекологии №2 Ташкентской медицинской академии, Узбекистан

Г.А. Ахмедова, ассистент кафедры акушерства и гинекологии №2 Ташкентской медицинской академии, Узбекистан

Преэклампсия и эклампсия являются самыми распространенными причинами гестационных осложнений как для матери, так и для плода. Как показали результаты конфиденциального аудита материнской смертности от преэклампсии в регионах России в 2016 г., основными причинами материнской смертности от преэклампсии/эклампсии являются отсутствие прогнозирования преэклампсии; запоздалая диагностика легкой преэклампсии и недооценка ее тяжести; недостаточное и несвоевременное обследование; запоздалое родоразрешение; прекращение магнезиальной терапии во время и после родоразрешения. Целью исследования стало изучение вопроса о необходимости лечения легкой преэклампсии, которую, согласно утвержденным Минздравом Республики Узбекистан клиническим протоколам, не нужно лечить, но необходимо наблюдать за артериальным давлением и протеинурией.

Под наблюдением находились 68 женщин в третьем триместре беременности, поступивших в отделение патологии акушерского комплекса 2-й клиники Ташкентской медицинской академии с диагнозом легкая преэклампсия. Женщины были разделены на две группы: 1 (группа сравнения) - 30 беременных с легкой преэклампсией, ведение которых осуществлялось согласно клиническим протоколам с наблюдением за артериальным давлением и протеинурией; 2 (основная группа) - 38 беременных с легкой преэклампсией, которые получали L-аргинин (Тивортин ${ }^{\odot}$ ) в сочетании с комплексом антиоксидантных витаминов.

В ходе исследования у 18 женщин группы сравнения было отмечено прогрессирование преэклампсии до уровня тяжелой, и после нагрузочной дозы магнезиальной терапии этих больных родоразрешали путем индукции родов или операции кесарева сечения. У пациенток основной группы, которым вводили Тивортин ${ }^{\oplus}$ и комплекс антиоксидантных витаминов, прогрессирования преэклампсии не наблюдалось и беременность пролонгировали до жизнеспособного срока плода.

Таким образом, авторы исследования приходят к выводу, что беременных с легкой преэклампсией с высоким риском развития тяжелой преэклампсии и эклампсии необходимо госпитализировать в стационар для полного обследования и проведения лечения путем введения аминокислоты (Тивортина) и комплекса антиоксидантных витаминов.

Ключевые слова: преэклампсия, эклампсия, лечение, Тивортин.

\section{ЧИ ПОТРІБНО ЛІКУВАТИ ЛЕГКУ ПРЕЕКЛАМПСІЮ?}

А.Х. Карімов, д. мед. н., професор кафедри акушерства і гінекології №2 Ташкентської медичної академії, Узбекистан

Г.А. Ахмедова, асистент кафедри акушерства і гінекології №2 Ташкентської медичної академії, Узбекистан

Прееклампсія й еклампсія $\epsilon$ найпоширенішими причинами гестаційних ускладнень як для матері, так і для плода. Як показали результати конфіденційного аудиту материнської смертності від прееклампсії в регіонах Росії в 2016 р., основними причинами материнської смертності від прееклампсії/еклампсії є відсутність прогнозування прееклампсії; запізніла діагностика легкої прееклампсії і недооцінювання ї̈ тяжкості; недостатнє та несвоєчасне обстеження; запізніле розродження; припинення магнезіальної терапії під час і після пологів. Метою дослідження стало вивчення питання про необхідність лікування легкої прееклампсії, яку, згідно із затвердженими Міністерством охорони здоров'я Республіки Узбекистан клінічними протоколами, не потрібно лікувати, але необхідно спостерігати за артеріальним тиском і протеїнурією.

Під спостереженням знаходилися 68 жінок у третьому триместрі вагітності, які поступили до відділення патології акушерського комплексу 2-ї клініки Ташкентської медичної академії з діагнозом легка прееклампсія. Жінки були розділені на дві групи: 1 (група порівняння) - 30 вагітних з легкою прееклампсією, ведення яких здійснювалося відповідно до клінічних протоколів з наглядом за артеріальним тиском і протеїнурією; 2 (основна група) - 38 вагітних з легкою прееклампсією, які отримували L-аргінін (Тівортін ${ }^{\odot}$ ) у поєднанні з комплексом антиоксидантних вітамінів.

Під час дослідження у 18 жінок групи порівняння було відзначено прогресування прееклампсії до рівня важкої, і після навантажувальної дози магнезіальної тераппї цих хворих розроджували шляхом індукції пологів або операції кесаревого розтину. В пацієнток основної групи, яким вводили Тівортін ${ }^{\odot}$ і комплекс антиоксидантних вітамінів, прогресування прееклампсії не спостерігалося і вагітність пролонгували до життєздатного терміну плода.

Таким чином, автори дослідження дійшли висновку, що вагітних із легкою прееклампсією $з$ високим ризиком розвитку тяжкої прееклампсії̆ й еклампсії необхідно госпіталізувати в стаціонар для повного обстеження і проведення лікування шляхом введення амінокислоти (Тівортіну) та комплексу антиоксидантних вітамінів.

Ключові слова: прееклампсія, еклампсія, лікування, Тівортін.

\section{IS IT NECESSARY TO TREAT THE MILD PREECLAMPSIA?}

A.H. Karimov, MD, professor at the Department of Obstetrics and Gynecology No. 2, Tashkent Medical Academy, Uzbekistan

G.A. Akhmedova, assistant at the Department of Obstetrics and Gynecology No. 2, Tashkent Medical Academy, Uzbekistan

Preeclampsia and eclampsia are the most common causes of gestational complications for both the mother and the fetus. As the results of a confidential audit of maternal deaths from preeclampsia in regions of Russia in 2016 showed, the main causes of maternal deaths from preeclampsia/eclampsia are the lack of prediction of preeclampsia; belated diagnosis of mild preeclampsia and underestimation of its severity; insufficient and untimely examination; belated delivery; cessation of magnesia therapy during and after delivery. The aim of the study was to research the need for the treatment of mild preeclampsia, which, according to the clinical protocols approved by the Ministry of Health of the Republic of Uzbekistan, should not be treated, but it is necessary to observing for arterial pressure and proteinuria.

Under observation were 68 women in the third trimester of pregnancy, admitted to the obstetrics department of the 2nd clinic of the Tashkent Medical Academy with a diagnosis of mild preeclampsia. Women were divided into two groups: 1 (comparison group) - 30 pregnant women with mild preeclampsia, administered according to clinical protocols with monitoring of arterial pressure and proteinuria; 2 (main group) - 38 pregnant women with mild preeclampsia who received L-arginine (Tivortin ${ }^{\circledast}$ ) in combination with a complex of antioxidant vitamins.

In the study, 18 women of the comparison group experienced progression of pre-eclampsia to severe, and after a loading dose of magnesium therapy these patients were delivered by induction of labor or a cesarean section. In patients of the main group who were injected with Tivortin ${ }^{\oplus}$ and a complex of antioxidant vitamins, the progression of preeclampsia was not observed and the pregnancy was prolonged until the viable period of the fetus.

Thus, the authors of the study conclude that pregnant women with mild preeclampsia with a high risk of developing severe preeclampsia and eclampsia must be hospitalized for inpatient examination and treatment by introducing an amino acid (Tivortin ${ }^{\oplus}$ ) and a complex of antioxidant vitamins.

Keywords: preeclampsia, eclampsia, treatment, Tivortin. 